\title{
The land surface mildly contaminated by $\mathrm{Hg}$
}

\author{
Dongfang Yang ${ }^{1,2,{ }^{*}}$, Haixia $\mathrm{Li}^{1}$, Dong Lin ${ }^{1}$, Longlei Zhang ${ }^{1}$, Qi Wang ${ }^{1}$ \\ ${ }^{1}$ Accountancy School, Xijing University, Xi'an 710123, China; \\ ${ }^{2}$ North China Sea Environmental Monitoring Center, SOA, Qingdao 266033, China;
}

\begin{abstract}
The Hg content in the waters of Jiaozhou Bay was within $0.010-0.060 \mu \mathrm{g} / \mathrm{L}$ in May, September and October 1993, which conforms to the seawater quality standards of Class I and II. It indicates that in the entire waters of Jiaozhou Bay, there were some water areas that did not get contaminated by $\mathrm{Hg}$ while some areas got mild contamination by $\mathrm{Hg}$ in May, September and October. In May, the variation range of $\mathrm{Hg}$ content in

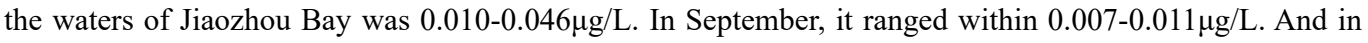
October, the content of $\mathrm{Hg}$ detected in the waters of Jiaozhou Bay was $0.060 \mu \mathrm{g} / \mathrm{L}$. There were three sources to transport $\mathrm{Hg}$ content, open sea currents, Licun river and the surface runoff. The $\mathrm{Hg}$ content from the transportation of open sea currents was $0.046 \mu \mathrm{g} / \mathrm{L}$, from the Licun river was $0.011 \mu \mathrm{g} / \mathrm{L}$ and from the surface runoff was $0.060 \mu \mathrm{g} / \mathrm{L}$. This paper builds a model block diagram to present the different paths and $\mathrm{Hg}$ contents that were input in the Jiaozhou Bay. In May, the open sea currents did not get any contamination of Hg; in August, the Licun river did not get any contamination of $\mathrm{Hg}$ as well; while in September, the surface runoff was mildly contaminated by $\mathrm{Hg}$. The author concluded two points about the migration of $\mathrm{Hg}$ content: 1) Human activities discharge $\mathrm{Hg}$ to the land so that the $\mathrm{Hg}$ content could directly run to the ocean through the surface runoff. As the $\mathrm{Hg}$ content transported by surface runoff was relatively high, it resulted that the nearshore waters got mild contamination of $\mathrm{Hg}$ content. On the other hand, the surface runoff transported $\mathrm{Hg}$ to rivers, resulting relatively low content of $\mathrm{Hg}$. Then rivers delivered the $\mathrm{Hg}$ content to nearshore waters, leading to a non-contaminated condition of rivers. 2) Human activities input $\mathrm{Hg}$ content to the ocean in a long period, resulting the increase of $\mathrm{Hg}$ content in the ocean. As the accumulation of $\mathrm{Hg}$ content in the ocean, the ocean got close to the mild contamination status.
\end{abstract}

\section{Introduction}

With the release of large amounts of $\mathrm{Hg}$ from land to the environment by many industries, $\mathrm{Hg}$ content has appeared on land, atmosphere, and oceans. The pollution degree and source of $\mathrm{Hg}$ content in the coastal waters has become everyone's concern [1-14]. Based on the survey data in 1993, the author studied the content, horizontal distribution and sources of $\mathrm{Hg}$ in the water body of Jiaozhou Bay. Further the author determined the water quality, source background and quantity of $\mathrm{Hg}$ in the water body of Jiaozhou Bay, providing scientific theoretical basis for the protection of the marine environment and the maintenance of sustainable ecological development.

\section{Survey waters, materials and methods}

\subsection{The natural environment of Jiaozhou Bay}

Jiaozhou Bay is located in the southern part of Shandong Peninsula. Its geographical position is between $120^{\circ} 04^{\prime}-$ $120^{\circ} 23^{\prime} \mathrm{E}$ and $35^{\circ} 58^{\prime}-36^{\circ} 18^{\prime} \mathrm{N}$. It is bounded by the line connecting Tuan Island and Xuejia Island, and is connected to the Yellow Sea. With an area of about $446 \mathrm{~km} 2$ and an average water depth of about $7 \mathrm{~m}$, it is a typical semi-enclosed bay. There are more than a dozen rivers entering the sea in Jiaozhou Bay, among which the Dagu River, Yang River and the Haibo River, Licun River and Loushan River in Qingdao City with larger runoff and sand content. These rivers are all seasonal rivers, and the river hydrological characteristics have obvious seasonal changes $[12,13]$.

\subsection{Materials and methods}

The survey data of PHC content in Jiaozhou Bay in May, September and October 1993 used in this study are provided by the North Sea Monitoring Center of the State Oceanic Administration. Seven stations were set up in the waters of Jiaozhou Bay to take water samples: stations H3101, H3102, H3103, H3104, H3105, H3106 and H3107 (Figure 1). Sampling was conducted three times in May, September and October 1993, respectively. Water samples were taken by the water depth (surface and bottom layers were taken when the depth $>10 \mathrm{~m}$, and only the surface layer was taken when the depth $<10 \mathrm{~m}$ ) for investigation and sampling. The survey of $\mathrm{Hg}$ content in Jiaozhou Bay water body was carried out according to the national

*dfyang dfyang@126.com 
standard method, recorded in the national Marine Monitoring Code (1991) [14].

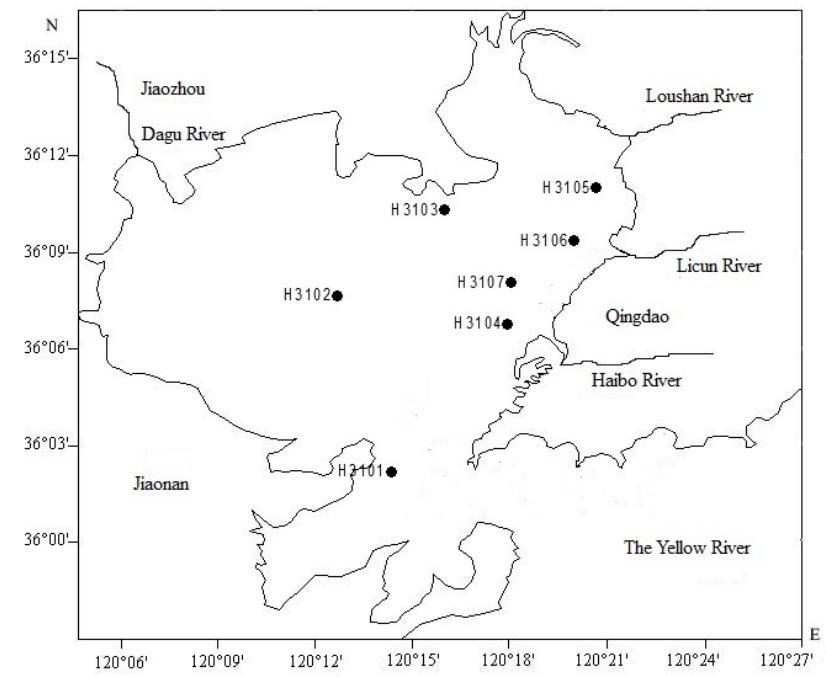

Fig.1 Investigation sites in Jiaozhou Bay

\section{Results}

\subsection{Hg content}

In terms of $\mathrm{Hg}$ content in the ocean, the nation has put forward the national seawater quality standards for Class I $(0.05 \mu \mathrm{g} / \mathrm{L})$, Class II $(0.20 \mu \mathrm{g} / \mathrm{L})$, and Class IV $(0.50 \mu \mathrm{g} / \mathrm{L})$. In May, September and October, the range of $\mathrm{Hg}$ content was $0.010-0.060 \mu \mathrm{g} / \mathrm{L}$, which had achieved the seawater quality standards of Class I and II.

In May, the variation range of $\mathrm{Hg}$ content in the waters of Jiaozhou Bay was $0.010-0.046 \mu \mathrm{g} / \mathrm{L}$ (Table 1), where the high value appeared in the month waters of Jiaozhou Bay. In the mouth waters of Jiaozhou Bay, station H3101, the $\mathrm{Hg}$ content in the waters was relatively high, which was $0.046 \mu \mathrm{g} / \mathrm{L}$, conforming to the seawater quality standard of Class I $(0.05 \mu \mathrm{g} / \mathrm{L})$. Except for the month waters, the $\mathrm{Hg}$ content was relatively low, less than $0.034 \mu \mathrm{g} / \mathrm{L}$, in other water areas such as the northeastern part, the northern part and the central part. It indicates that the water quality in the northeastern area, northern area and the central area, in terms of $\mathrm{Hg}$, was great and achieved the national seawater quality standard of Class I.

In September, the variation range of $\mathrm{Hg}$ content in the waters of Jiaozhou Bay was $0.007-0.011 \mu \mathrm{g} / \mathrm{L}$ (Table 1), where the high value appeared in the coastal waters of the estuary of Licun river. In the coastal waters of the estuary of Licun river, station $\mathrm{H} 3106$, the $\mathrm{Hg}$ content in the waters was very low, which was $0.011 \mu \mathrm{g} / \mathrm{L}$, conforming to the seawater quality standard of Class I $(0.05 \mu \mathrm{g} / \mathrm{L})$. Except for the coastal waters in the estuary of Licun river, the $\mathrm{Hg}$ content was relatively low, less than $0.008 \mu \mathrm{g} / \mathrm{L}$, in other water areas such as the northern part and the southern part, conforming to the seawater quality standard of Class I. In terms of $\mathrm{Hg}$, the waters quality was great and achieved the national seawater quality standard of Class I.

In October, the variation range of $\mathrm{Hg}$ content in the waters of Jiaozhou Bay was $0.060 \mu \mathrm{g} / \mathrm{L}$ (Table 1), where the high value appeared in the coaster waters of the north of Jiaozhou Bay. In the coaster waters of the north of Jiaozhou Bay, station H3103, the Hg content in the waters was relatively high, which was $0.060 \mu \mathrm{g} / \mathrm{L}$, conforming to the seawater quality standard of Class II $(0.05 \mu \mathrm{g} / \mathrm{L})$. It indicates that the water quality in the northern coaster area, in terms of $\mathrm{Hg}$, achieved the national seawater quality standard of Class II $(5.00 \mu \mathrm{g} / \mathrm{L})$.

Therefore, the variation range of $\mathrm{Hg}$ content in the waters of Jiaozhou Bay in May, September and October was $0.010-0.060 \mu \mathrm{g} / \mathrm{L}$, conforming to the seawater quality standards of Class I and II. It indicates that in terms of $\mathrm{Hg}$, the waters quality in the entire waters of Jiaozhou Bay in May, September and October achieved seawater quality standard of Class I and II. The water did not get any pollution and mild contamination by $\mathrm{Hg}$.

Table 1 The surface water quality in Jiaozhou bay in May, September and October

\begin{tabular}{|c|c|c|c|}
\hline & May & September & October \\
\hline $\mathrm{Hg}$ content in & $0.010-$ & $0.007-0.011$ & 0.060 \\
seawaters $\mu \mathrm{g} \cdot \mathrm{L}-1$ & 0.046 & Class I & Class I \\
National seawater & Class I & & \\
quality standards & & & \\
\hline
\end{tabular}

\subsection{Horizontal distribution in the surface layer}

In May, in the mouth waters of Jiaozhou Bay, station $\mathrm{H} 3101$, the $\mathrm{Hg}$ content reached a relatively high level of $0.046 \mu \mathrm{g} / \mathrm{L}$. A high-content area of $\mathrm{Hg}$ was formed with the mouth water area as the center, forming a series of parallel lines with different gradients. The $\mathrm{Hg}$ content decreased from the high content of $0.046 \mu \mathrm{g} / \mathrm{L}$ in the center to the bay along the gradient, to $0.030 \mu \mathrm{g} / \mathrm{L}$ in the eastern waters of the bay, to $0.010 \mu \mathrm{g} / \mathrm{L}$ in the northeastern waters (Figure 2).

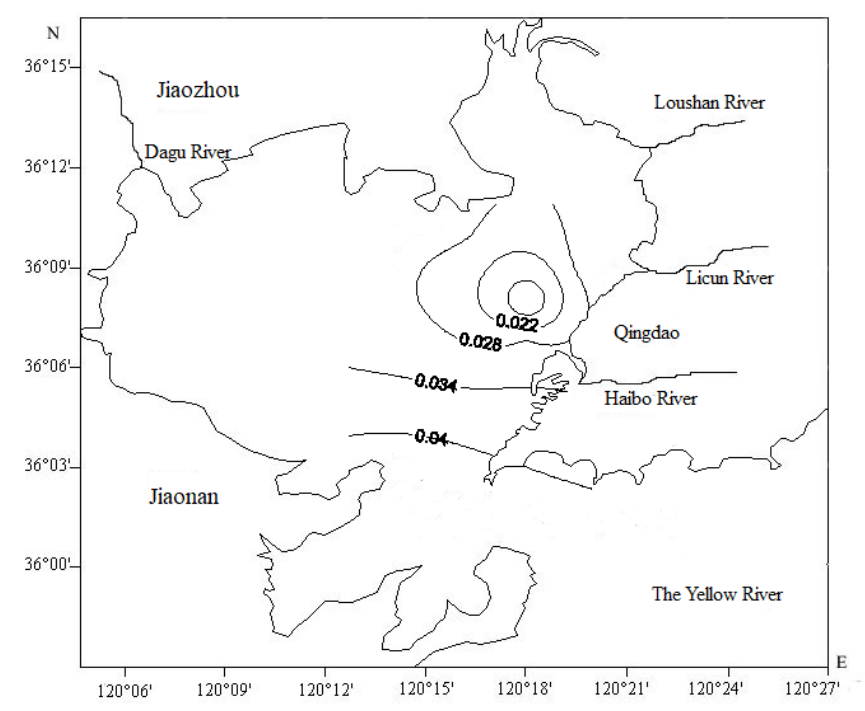

Fig. $2 \mathrm{Hg}$ content distribution in the surface layer of Jiaozhou Bay in May $(\mu \mathrm{g} / \mathrm{L})$

In September, in the coastal waters of the Licun River in Jiaozhou Bay, station H3106, the Hg content reached a relatively high value, $0.011 \mu \mathrm{g} / \mathrm{L}$, forming a high $\mathrm{Hg}$ 
content area with the eastern waters as the center, and a series of semi-concentric circles with different gradients. The $\mathrm{Hg}$ content decreased from the high content of $0.011 \mu \mathrm{g} / \mathrm{L}$ in the center along the gradient to $0.007 \mu \mathrm{g} / \mathrm{L}$ in the southwest waters (Figure 3).

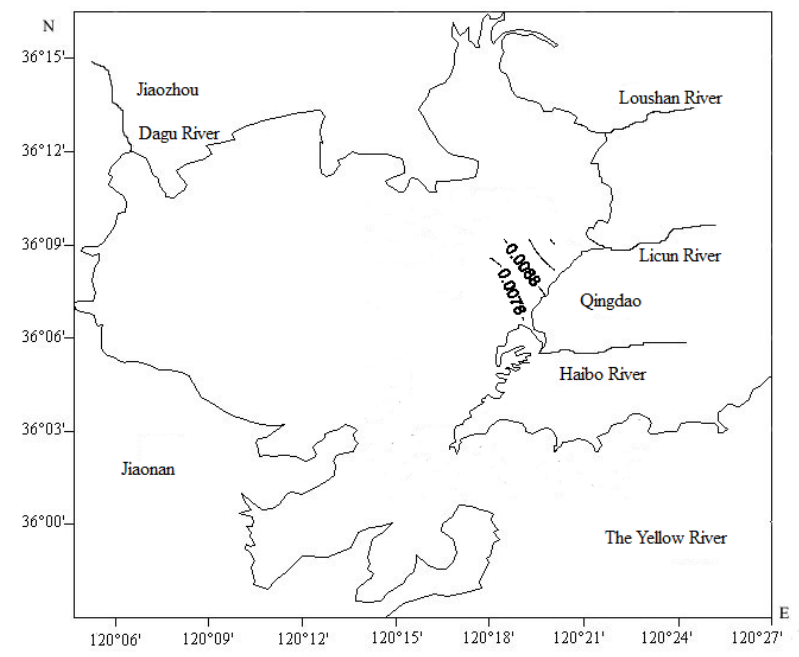

Fig.3 Hg content distribution in the surface layer of Jiaozhou Bay in September $(\mu \mathrm{g} / \mathrm{L})$

In October, in the coastal waters of northern part of Jiaozhou Bay, station H3103, the Hg content in the water body was relatively high, $0.060 \mu \mathrm{g} / \mathrm{L}$. A high content area of $\mathrm{Hg}$ was formed with the northern waters of the bay as the center, forming a series of parallel lines with different gradients. The $\mathrm{Hg}$ content decreased from the high content of $0.060 \mu \mathrm{g} / \mathrm{L}$ in the center to the waters of the southeast of the bay along the gradient.

\section{Discussion}

\subsection{Water quality}

The variation range of $\mathrm{Hg}$ content in the waters of Jiaozhou Bay in May, September and October was 0.010$0.060 \mu \mathrm{g} / \mathrm{L}$, conforming to the seawater quality standards of Class I and II. It indicates that in terms of $\mathrm{Hg}$, in the entire waters of Jiaozhou Bay in May, September and October, some water areas did not get any contamination by $\mathrm{Hg}$, while some areas were mildly contaminated by $\mathrm{Hg}$.

In May, the variation range of $\mathrm{Hg}$ content in the waters of Jiaozhou Bay was $0.010-0.046 \mu \mathrm{g} / \mathrm{L}$, indicating that the waters of Jiaozhou Bay did not get any contamination by $\mathrm{Hg}$. In the mouth waters of Jiaozhou Bay, the $\mathrm{Hg}$ content reached a relatively high value, $0.046 \mu \mathrm{g} / \mathrm{L}$, which indicated that the water quality achieved the seawater quality standard of Class I and the water did not get any contamination by $\mathrm{Hg}$. Except for the waters in the southwest of Jiaozhou Bay, the Hg content was relatively low in other parts of Jiaozhou Bay, far meeting the seawater quality standard of Class I. The water was clean and did not get any contamination of $\mathrm{Hg}$.

In September, the variation range of $\mathrm{Hg}$ content in the waters of Jiaozhou Bay was $0.007-0.011 \mu \mathrm{g} / \mathrm{L}$, indicating that the waters of Jiaozhou Bay did not get any contamination by $\mathrm{Hg}$. In the coastal water of the estuary of Licun river, the $\mathrm{Hg}$ content reached a very low level, $0.011 \mu \mathrm{g} / \mathrm{L}$, which indicated the water quality achieved the seawater quality standard of Class I and the water did not get any contamination by $\mathrm{Hg}$. Except for the coastal waters of the estuary of Licun river, the $\mathrm{Hg}$ content was much lower, far meeting the seawater quality standard of Class I. The water was clean and did not get any contamination of $\mathrm{Hg}$.

In October, the variation range of $\mathrm{Hg}$ content in the waters of Jiaozhou Bay was $0.060 \mu \mathrm{g} / \mathrm{L}$, which indicated that the waters of Jiaozhou Bay did get contaminated by $\mathrm{Hg}$. The $\mathrm{Hg}$ content in the northern waters of Jiaozhou Bay reached a relatively high level, $0.060 \mu \mathrm{g} / \mathrm{L}$, presenting that the water quality achieved the seawater quality standard of Class II and the water quality was mildly contaminated by $\mathrm{Hg}$.

\subsection{Sources}

In May, it formed a high $\mathrm{Hg}$ content area in the mouth of southwest of Jiaozhou Bay, which indicated that the $\mathrm{Hg}$ was sourced from the transportation of open sea currents with a relatively low content of $0.046 \mu \mathrm{g} / \mathrm{L}$.

In September, it formed a high $\mathrm{Hg}$ content area in the coastal waters of the estuary of Licun river, which indicated that the $\mathrm{Hg}$ was sourced from the transportation of Licun river with a relatively low content of $0.011 \mu \mathrm{g} / \mathrm{L}$.

In October, it formed a high $\mathrm{Hg}$ content area in the coastal waters of the north of Jiaozhou Bay, which indicated that the $\mathrm{Hg}$ was sourced from the surface runoff with a relatively high content of $0.060 \mu \mathrm{g} / \mathrm{L}$.

Therefore, the $\mathrm{Hg}$ content transported by the open sea currents to Jiaozhou Bay was $0.046 \mu \mathrm{g} / \mathrm{L}$ in May, conforming to the national seawater quality standard of Class I, $0.05 \mu \mathrm{g} / \mathrm{L}$. It indicated that the open sea currents did not get any contamination of $\mathrm{Hg}$ (Table 2). The $\mathrm{Hg}$ content transported by the Licun river was $0.011 \mu \mathrm{g} / \mathrm{L}$ in September, conforming to the national seawater quality standard of Class I, $0.05 \mu \mathrm{g} / \mathrm{L}$. It indicated that the Licun river did not get any contamination of $\mathrm{Hg}$ (Table 2). The $\mathrm{Hg}$ content transported by the surface runoff was $0.060 \mu \mathrm{g} / \mathrm{L}$ in October, conforming to the national seawater quality standard of Class II, $0.05 \mu \mathrm{g} / \mathrm{L}$. It indicated that the land surface runoff did get mild contamination of $\mathrm{Hg}$ (Table 2).

Table 2 The Hg contents from different sources in Jiaozhou bay

\begin{tabular}{|c|c|c|c|}
\hline Time & May & August & October \\
\hline $\begin{array}{c}\text { Various } \\
\text { sources }\end{array}$ & $\begin{array}{c}\text { Open sea } \\
\text { currents } \\
\text { transportation }\end{array}$ & $\begin{array}{c}\text { Licun River } \\
\text { transportation }\end{array}$ & $\begin{array}{c}\text { Surface runoff } \\
\text { transportation }\end{array}$ \\
\hline $\begin{array}{c}\mathrm{Hg} \text { content } \\
/ \mu \mathrm{g} \cdot \mathrm{L}-1\end{array}$ & 0.046 & 0.011 & 0.060 \\
\hline
\end{tabular}

\subsection{The model block diagram of transportation}

There were three sources to transport $\mathrm{Hg}$ content, open sea currents, Licun river and the land surface runoff. The $\mathrm{Hg}$ content from the transportation of open sea currents was $0.046 \mu \mathrm{g} / \mathrm{L}$, from the Licun river was $0.011 \mu \mathrm{g} / \mathrm{L}$ and from 
the surface runoff was $0.060 \mu \mathrm{g} / \mathrm{L}$. This paper establishes a block diagram to present different paths and contents of $\mathrm{Hg}$ during the input process (Figure 4). Thus, it is able to quantitatively reveal the migration of $\mathrm{Hg}$ content through the discharge of human activities to land and ocean.

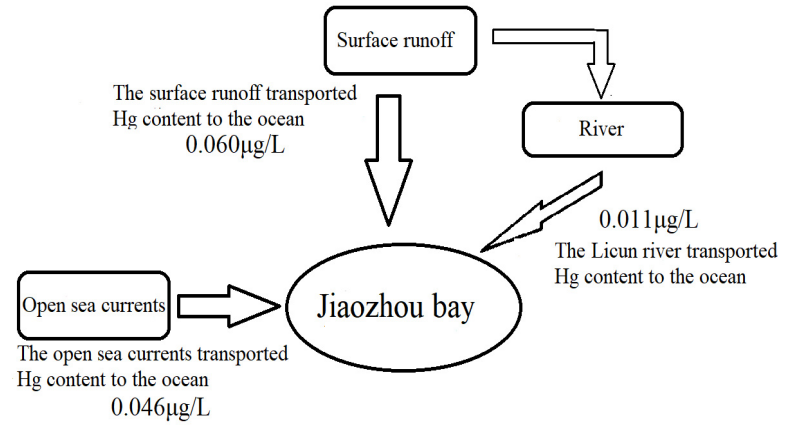

Fig.4 Main sources of $\mathrm{Hg}$ content transported to Jiaozhou bay $(\mu \mathrm{g} / \mathrm{L})$

In May, the $\mathrm{Hg}$ content transported by the open sea currents was $0.046 \mu \mathrm{g} / \mathrm{L}$, revealing that the $\mathrm{Hg}$ content transported by this way was relatively low and the open sea currents did not get contaminated by $\mathrm{Hg}$.

In September, the Hg content transported by the Licun River was $0.011 \mu \mathrm{g} / \mathrm{L}$, revealing that the $\mathrm{Hg}$ content transported by this way was very low and the Licun River did not get contaminated by $\mathrm{Hg}$.

In October, the $\mathrm{Hg}$ content transported by the land surface runoff was $0.060 \mu \mathrm{g} / \mathrm{L}$, revealing that the $\mathrm{Hg}$ content transported by this way was relatively high and the land surface runoff did get mildly contaminated by $\mathrm{Hg}$.

\subsection{The variation in content transported}

In May, the $\mathrm{Hg}$ content transported by the open sea currents was $0.046 \mu \mathrm{g} / \mathrm{L}$, and the open sea currents did not get contaminated by $\mathrm{Hg}$. This reveals that after a long period of time, humans input $\mathrm{Hg}$ into the ocean, resulting in an increase in the $\mathrm{Hg}$ content of the ocean. Although it was not polluted by the $\mathrm{Hg}$ content, the $\mathrm{Hg}$ content made the ocean close to mild contamination.

In September, the Hg content transported by the Licun River was $0.011 \mu \mathrm{g} / \mathrm{L}$, and the Licun River did not get contaminated by $\mathrm{Hg}$. This reveals that humans first discharged $\mathrm{Hg}$ to the land, and then $\mathrm{Hg}$ was transported through rivers to the coastal waters of the ocean, and then the $\mathrm{Hg}$ content was relatively low when imported into the ocean through a long path.

In October, the $\mathrm{Hg}$ content transported by the land surface runoff was $0.060 \mu \mathrm{g} / \mathrm{L}$, and the land surface runoff did get mildly contaminated by $\mathrm{Hg}$. This reveals that the $\mathrm{Hg}$ content discharged by humans to the land was relatively high, and the land surface was at least slightly polluted by the $\mathrm{Hg}$ content. The direct discharge of $\mathrm{Hg}$ content to the ocean through surface runoff was also relatively high. In this way, the coastal waters in the northern part of Jiaozhou Bay were mildly contaminated by $\mathrm{Hg}$ content.

Therefore, the author concluded two conclusions: 1) From the perspective of the path of discharge, human activities discharge $\mathrm{Hg}$ to the land so that the $\mathrm{Hg}$ content could directly run to the ocean through the surface runoff. As the $\mathrm{Hg}$ content transported by surface runoff was relatively high, it resulted that the nearshore waters got mild contamination of $\mathrm{Hg}$ content. On the other hand, the surface runoff transported $\mathrm{Hg}$ to rivers, resulting relatively low content of $\mathrm{Hg}$. Then rivers delivered the $\mathrm{Hg}$ content to nearshore waters, leading to a non-contaminated condition of rivers. 2) Human activities import $\mathrm{Hg}$ content to the ocean in a long period, resulting the increase of $\mathrm{Hg}$ content in the ocean. As the accumulation of $\mathrm{Hg}$ content in the ocean, the ocean got close to the mild contamination status.

\section{Conclusion}

The variation range of $\mathrm{Hg}$ content in the waters of Jiaozhou Bay in May, September and October was 0.010$0.060 \mu \mathrm{g} / \mathrm{L}$, conforming to the seawater quality standards of Class I and II. It indicates that in terms of $\mathrm{Hg}$, in the entire waters of Jiaozhou Bay in May, September and October, some water areas did not get any contamination by $\mathrm{Hg}$, while some areas were mildly contaminated by $\mathrm{Hg}$.

In May, the variation range of $\mathrm{Hg}$ content in the waters of Jiaozhou Bay was $0.010-0.046 \mu \mathrm{g} / \mathrm{L}$, indicating that the waters of Jiaozhou Bay did not get any contamination by $\mathrm{Hg}$. In the mouth waters of Jiaozhou Bay, the Hg content reached a relatively high value, $0.046 \mu \mathrm{g} / \mathrm{L}$, while in other parts of Jiaozhou Bay, the $\mathrm{Hg}$ content was relatively low.

In September, the variation range of $\mathrm{Hg}$ content in the waters of Jiaozhou Bay was $0.007-0.011 \mu \mathrm{g} / \mathrm{L}$, indicating that the waters of Jiaozhou Bay did not get any contamination by $\mathrm{Hg}$. In the coastal water of the estuary of Licun River, the $\mathrm{Hg}$ content reached a very low level, $0.011 \mu \mathrm{g} / \mathrm{L}$, while in the other parts of Jiaozhou Bay, the $\mathrm{Hg}$ content was much lower.

In October, the variation range of $\mathrm{Hg}$ content in the waters of Jiaozhou Bay was $0.060 \mu \mathrm{g} / \mathrm{L}$, which indicated that the waters of Jiaozhou Bay did get contaminated by $\mathrm{Hg}$. The Hg content in the northern waters of Jiaozhou Bay reached a relatively high level, $0.060 \mu \mathrm{g} / \mathrm{L}$, and the water quality was mildly contaminated by $\mathrm{Hg}$.

There were three sources to transport Hg content, open sea currents, Licun River and the land surface runoff. The $\mathrm{Hg}$ content from the transportation of open sea currents was $0.046 \mu \mathrm{g} / \mathrm{L}$, from the Licun River was $0.011 \mu \mathrm{g} / \mathrm{L}$ and from the surface runoff was $0.060 \mu \mathrm{g} / \mathrm{L}$. This paper establishes a block diagram to present different paths and contents of $\mathrm{Hg}$ during the input process. Thus, it is able to quantitatively reveal the migration of $\mathrm{Hg}$ content through the discharge of human activities to land and ocean.

Therefore, in May, the open sea currents did not get any contamination of $\mathrm{Hg}$; in August, the Licun River did not get any contamination of $\mathrm{Hg}$ as well; while in September, the surface runoff was mildly contaminated by $\mathrm{Hg}$.

The author concluded two points about the migration of $\mathrm{Hg}$ content: 1) Human activities discharge $\mathrm{Hg}$ to the land so that the $\mathrm{Hg}$ content could directly run to the ocean through the surface runoff. As the $\mathrm{Hg}$ content transported by surface runoff was relatively high, it resulted that the nearshore waters got mild contamination of $\mathrm{Hg}$ content. On the other hand, the surface runoff transported $\mathrm{Hg}$ to 
rivers, resulting relatively low content of $\mathrm{Hg}$. Then rivers delivered the $\mathrm{Hg}$ content to nearshore waters, leading to a non-contaminated condition of rivers. 2) Human activities input $\mathrm{Hg}$ content to the ocean in a long period, resulting the increase of $\mathrm{Hg}$ content in the ocean. As the accumulation of $\mathrm{Hg}$ content in the ocean, the ocean got close to the mild contamination status.

\section{Acknowledgement}

This research was sponsored by Research Projects of Guizhou Nationalities University ([2014]02), Research Projects of Guizhou Province Ministry of Education (KY [2014] 266), Research Projects of Guizhou Province Ministry of Science and Technology (LH [2014] 7376).

\section{References}

1. Dongfang Yang, Zhenhui Gao. Marine Bay Ecology [M]. Beijing: China Culture Publishing House. 2006.

2. Dongfang Yang, Zhenqing Miao. Marine Bay Ecology (Volume 1) [M]. Beijing: China Ocean Press, 2010

3. Dongfang Yang, Zhenhui Gao. Marine Bay Ecology (Volume 2) [M]. Beijing: China Ocean Press, 2010

4. Yu Chen, Zhenhui Gao, Yanheng Qu, Dongfang Yang and Hongxia Tang. Mercury distribution in the Jiaozhou Bay [J]. Chin. J. Oceanol. Limnol. 2007, 25(4): 455-458.

5. Dongfang Yang, Hairong Cao, Zhenhui Gao, Qing Lu, Yanfeng Qu. Hg in Jiaozhou Bay I.Distribution and transition [J]. Marine Environmental Science, 2008, 27 (1): 37-39.

6. Dongfang Yang, Leilei Wang, Zhenhui Gao, Lian Ju, Jiping Zeng. Hg in Jiaozhou Bay II. Distribution and pollution sources $[\mathrm{J}]$. Marine Environmental Science, 2009, 28 (5): 501-505.

7. Yu Chen, Qinjiang Zhang, Junhui Guo, Qiang Shi, Dongfang Yang. Distribution and seasonal changes of $\mathrm{Hg}$ in the Jiaozhou Bay [J]. Ocean development and management, 2013, 30(6): 81-83.

8. Dongfang Yang, Peiyan Sun, Lian Ju, Yuhui Zhao, Yanfeng Qu. Content and Distribution of $\mathrm{Hg}$ in the Water of the Jiaozhou Bay [J]. Coastal Engineering, 2013, 32(4): 65-76.

9. Dongfang Yang, Zijun Xu, Yanfeng Qu, Yanrong Zhou, Fei Teng. Distribution and Input Way of $\mathrm{Hg}$ in the Jiaozhou Bay [J]. Coastal Engineering, 2014, 33 (1): 67-78.

10. Yu Chen, Yanfeng Qu, Renlin Pei and Dongfang Yang. Effect of $\mathrm{Hg}$ in Jiaozhou Bay waters- The aquatic transfer process $[\mathrm{J}]$. Advanced Materials Research Vols.955-959. 2014, 2491-2495.

11. Dongfang Yang, Sixi Zhu, Fengyou Wang, Xiuqin Yang and Yunjie Wu. Effect of $\mathrm{Hg}$ in Jiaozhou Bay waters- The land transfer process[J]. Advanced Materials Research Vols.955-959. 2014, 2496-2500.

12. Dongfang Yang, Sixi. Zhu, Fengyou Wang,
Huazhoung $\mathrm{He}$ and Yunjie Wu. Effect of $\mathrm{Hg}$ in Jiaozhou Bay waters- The Temporal variation of the $\mathrm{Hg}$ content $[\mathrm{J}]$. Applied Mechanics and Materials Vols.556-562. 2014, 633-636.

13. Dongfang Yang, Fengyou Wang, Huazhong He, Youfu Wu and Sixi Zhu. Effect of Hg in Jiaozhou Bay waters- The change process of the $\mathrm{Hg}$ pollution sources[J]. Advanced Materials Research Vols.955959. 2014, 1443-1447.

14. Dongfang Yang, Xiao Geng, Yanfeng Qu, Hongyan Bai, Zijun $\mathrm{Xu}$. Distribution and Gravity Characteristics of $\mathrm{Hg}$ (Heavy Metal) in the Waterbody of Jiaozhou Bay [J]. Ocean Development and Management, 2014, 31 (12): 71-77.

15. YANG D F, CHEN Y, GAO Z H, et al. Silicon Limitation on primary production and its destiny in Jiaozhou Bay, China IV transect offshore the coast with estuaries [J]. Chin. J. Oceanol. Limnol. 2005, 23(1): 72-90.

16. Dongfang Yang, Fan Wang, Zhenhui Gao, et al. Ecological Phenomena of Phytoplankton in Jiaozhou Bay [J]. Marine Science, 2004, 28 (6): 71-74.

17. State Oceanic Administration. The Specification for Marine Monitoring [Z]. Beijing: China Ocean Press, 1991. 